RESEARCHARTICLE

\title{
Exploring the Experiences of Female Graduate Students in African Universities: Questions about Voice, Power, and Responsibility
}

\author{
Phil E. Okeke-Ihejirika ${ }^{1 *}$, Sibusiso Moyo ${ }^{2}$, and Henriëtte Van Den Berg ${ }^{3}$ \\ ${ }^{1}$ Womens \& Gender Studies, University of Alberta, Canada \\ ${ }^{2}$ Institute for Systems Science, Durban University of Technology, South Africa \\ ${ }^{3}$ University of the Free State, South Africa
}

\begin{abstract}
Consistent economic downturns, political uprisings, and social upheavals from the 1980s have significantly depleted the quality of higher education in Africa, particularly graduate training. While remarkable strides in graduate training have been made in countries such as South Africa relative to other parts of the continent, policy and funding challenges continue to threaten the quality of students and programs. Over the past two decades, new forms of institutional collaborations aimed at revamping graduate training in subSaharan Africa have emerged. Debates on how to revamp the higher education system are on going among scholars, policymakers, administrators, and funders, but minimal attention is paid to the students' voices, particularly women's that speak to the dire conditions under which graduate training is carried out. To spur more discussion about this gap in literature, we conducted focus group discussions with female graduate students in four higher education institutions in Nigeria and South Africa.

Our participants identified five major challenges that graduate students often wrestle with: financial challenges, limited sources of and dated curricular materials, institutional students as well as between students and scholars. These challenges, our participants assert, often place female graduate students in a more vulnerable position than their male counterparts. Our findings, though preliminary, point to the need to actively engage students, especially women, in academic debates and initiatives aimed at improving graduate training in Africa.
\end{abstract} Open Access

Citation: Okeke-Ihejirika, PE, Moyo S, Van Den Berg H. Exploring the Experiences of Female Graduate Students in African Universities: Questions about Voice, Power, and Responsibility. Gender and Women's Studies. 2019; 2(3):1.

Received: November 20, 2018

Accepted: May 27, 2019

Published: June 21, 2019

Copyright: ๑ 2019 Okeke-Ihejirika PE. This is an open access article distributed under the terms of the Creative Commons Attribution License, which permits unrestricted use, distribution, and reproduction in any medium, provided the original author and source are credited.

Corresponding author:

Phil E. Okeke-Ihejirika, Womens \&

Gender Studies, University of Alberta,

Canada

E-mail:pokeke@ualberta.ca

\section{Keywords}

Higher education; Graduate Training; Student Voice; Gender inequalities; Power Relations

\section{Introduction}

Despite the globally unimpressive economic trends that characterize the $21^{\text {st }}$ century, a significant number of Western funding agencies have sustained and, in some cases, expanded their collaborations with Sub-Saharan African higher education institutions as well as major research centers. For instance, since the mid-1940s, Fulbright, the United States' most prominent exchange program, has provided scholars in six global regions, including Sub-African Africa, the opportunity to study, teach, and conduct research. Similarly, the Carnegie African Diaspora Fellowship Program, initiated in 2013, aims to improve graduate training, curriculum development, and student mentoring through institutional collaboration between African-born scholars in the United States and Canada and their counterparts in Ghana, Kenya, Nigeria, South Africa, Tanzania, and Uganda (CADFP, 2018). Similarly, in 2015 Sweden and Uganda signed a five-year agreement to collaborate on tertiary education 
initiatives to enhance, among other things, graduate training outcomes for graduate students (Tuhereze, 2015). South African universities have equally benefitted from a large number of international research collaborations and capacity-building programs funded by agencies such as the Ford Foundation, Andrew Mellon Foundation, and the Erasmus Mundus Program; these initiatives have spurred the expansion of graduate cohorts and research supervision capacity (Cloete, Mouton, \& Sheppard, 2015, p. 233). Indeed, international collaboration and funding form part of the broader strategic initiatives that contribute to the positive ratings (top 500 in the world) of at least five South African universities in global university rankings (Shanghai, 2017).

Contributors to the debate on Africa's higher education have long recognized the need to identify innovative ways to confront the daunting challenges created by history, including limitations of an education system that is ill-equipped to address development issues and the crisis of youth unemployment (African Higher Education Summit, 2015; Adeogun, 2006; Teferra \& Altbach, 2003; Ikejiani, 1960). Other critics consider the task of developing a knowledge economy that embraces an outward-looking collaborative stance (Shrivastava \& Shrivastava, 2014; Jowi, 2012; Ondari-Okemwa, 2011). This shift, proponents argue, is necessary because public funding will neither lend itself to, nor be able to shoulder, the bold moves that are needed to revamp and transform the system. In addition, the world of teaching and research, especially in the "ivory tower," is increasingly an internationalized and communal endeavor that requires local and global networks of actors (Akuffo et al., 2014; Cherney, Povey, Boreham, Ferguson, \& Head, 2015; Woolley, Sánchez-Barrioluengo, Marceau, \& Turpin,2015). In other words, African institutions must be ready to respond to local knowledge demand, seek allies at home and abroad for its transformation agenda, and redefine their funding base in a manner that would afford them significant independence to assert a new agenda (Johnson \& Hoba, 2015).

It is also important to note that debates on how to transform Africa's higher education have also in many ways highlighted the centrality of gender as a crucial entry point into making system-wide changes. Prominent critics of systemic gender inequities in Africa's higher education have consistently emphasized the historical disadvantages African women face, attributable to culture, colonization, and capitalist expansion (Aina, 2010; Odejidi, Akanji, \& Odekunle, 2006; Morley, 2006; Mama, 2003). Other scholars in the field call for broader understandings of gender in both analytical and constitutive terms by drawing attention to the unique ways that gender frames institutional cultures and administrative structures of African higher academies (Okeke-Ihejirika, 2017; Seshoka, 2014; Govinder, Zondo, \& Makgoba, 2013). Financial and social barriers maintain the under representation of females in Nigerian higher education institutions including gender stereotyping, childcare and family responsibilities, violence against women in universities as well as a lack of role models (Desmennu \& Owoaje, 2018). South African universities have seen a significant increase in female postgraduate enrollments and graduates. Cloete, Mouton and Sheppard (2015) reported a $16.1 \%$ growth of female doctoral graduates for the period 2000 to 2012 . The growth rate for African females from other African countries was $20.9 \%$. This shows a positive trend in female participation and success in South Africa. Many scholars insist that the quest for new visions that could propel a renaissance, as well as the search for best practices that will enhance current graduate training, have not paid sufficient attention to the continual reproduction of systemic inequalities, particularly in the experiences of female students (Frick, Motshoane, McMaster \& Murphy, 2016).

These critiquesde monstrate the urgency of change. The threats that these challenges poseto Africa's higher education in the $21^{\text {st }}$ century cannot be overstated. However, it is disconcerting to note that the literature on Africa's higher education has not captured, the rich insights that graduate students, male and female alike, can provide both as experienced knowers and principal stakeholders. This lack of voice is worrying because African graduate students, as shown in this study, wrestle with some fundamental defects in the system, which, we argue, are grossly minimized by the priorities set by better-positioned stakeholders (Gachago, 2016).

As a first step in addressing this gap in the literature, our study explored the experiences of female graduate students in four higher education institutions in Nigeria and South Africa. This project was an integral part of a collaborative project on graduate training funded by the Carnegie Corporation, the Council for the Development of Social Science Research in Africa 
(CODESRIA), and the four participating institutions of higher education between 2015 and 2016. Given the sensitive nature of some of the issues discussed by the participants, the authors have assigned arbitrary labels to each institution to maintain confidentiality. The institutions are therefore identified as FA01 and FA02 in Nigeria, and FA03 and Fa04 in South Africa. This study provides initial data for a comprehensive review of existing support systems for graduate training in Africa.

\section{Review of Literature}

Although relatively sparse, the broader literature on higher education in Africa has, in recent times, waded into debates on student supervision (Muraraneza, Mtshali, \& Mthembu, 2016), institutional ranking (Ntshoe \& Selesho, 2014; Dlamini, 2016), access to and utility of higher education (Allais, 2017; llie \& Rose, 2016; Oketch, 2016), entrepreneurial education (AmadiEchendu, Phillips, Kudakwashe, \& Visser, 2016), and curriculum internationalization, among others (Gwakwa, 2016; Higgs, 2016). Most of these debates, however, have not incorporated student voice as a critical knowledge base for institutional transformation. A handful of scholars have assessed the challenges and impact of emerging trends in graduate training, including the use of mobile devices, emergence of research repositories, the rising emphasis on community engagement, and new forms of institutional partnerships as integral elements in knowledge production and utilization that should undergird any efforts to mobilize capacities and opportunities for development (Kaliisa \& Picard, 2017; Mtebe \& Raisamo, 2014; Van Wyk \&. du Toit, 2016). A good number of these studies re-echo the endemic problems posed by shortfalls in funding, weak infrastructural base, as well as limited administrative and academic support (Francis, Kilonzo \& Nyamukondiwa, 2016) as serious challenges that have "serious implications...not only for research output in the form of publications, but also for the training of graduate students in the country" (Illing, 2012, p.5). Proponents of student participation in institutional administration and governance call for critical reviews that could produce the appropriate frameworks for incorporating student voice as a necessary prerequisite for "intellectual accountability" in scholarly communities (Sall \& Oanda, 2014, p.106).

Except for a number of studies on South Africa, existing literature is virtually silent on the matter of student voice in graduate training. Clowes and Shefer's (2013) study of graduate supervision emphasizes the significance of co-authorship between supervisors and students. Despite the challenges such scholarly collaborations may pose, Clowes and Shefer argue that students consider these hands-on experiences with senior academics an enriching and empowering component of training that should provide them with the basic skill sets for independent thought. A more recent study on the relationship between supervisors and postgraduate nursing students highlights the personal and professional qualities of graduate supervisors as crucial factors that significantly influence successful supervisory relationships (Wyk, Coetzee, Havenga, \& Heyns, 2016). Writing is highlighted as an important skill that significantly impacts both students' successful completion of their training and their chances of embarking on an academic career path (Archer, 2010). In this regard, writing centers are well positioned not only to improve students' writing proficiency but also to create interdisciplinary spaces that could enhance the emergence of "coherent communities of researchers and writers." (Archer, 2010, p.508).

In building this literature, we argue, it is important to begin with studies that capture firsthand personal accounts of students' experiences of graduate training, particularly the challenges they face and the insights they offer to enhance the programs. Thus, our study seeks to answer the following research questions: What challenges do female African students face as graduate students in African universities? How do African female graduate students deal with these challenges? What changes can (or need to) be made to improve graduate training programs for female African postgraduate students in African universities?

\section{Theoretical Framework}

We place our study within a postcolonial feminist perspective that rejects the homogenization of the experiences outside women outside the western mainstream. Their experiences embody diverse histories and circumstances (Mohanty, 1988). African female graduate students are a diverse group; their experiences are mediated by class, race, religion, and so on, but we focus on their commonalities, including (i) a common experience of 
being "gendered" and racialized by culture, colonization, and capitalism (Kandiyoti, 2010); (ii) structures changes in gender roles within and outside the family that impact on women's quality of life and access to social opportunities;(iii) the history, culture, and social circumstances that often privilege men over women in higher education. Moreover, we emphasize the importance of African women's voices, cultural knowledge, agency, and resilience in engaging life's challenges (Kandiyoti, 2010). We also realize that, as researchers, we must also contend with fundamental questions about voice, power, and responsibility as the "official" interpreters of African women's experiences. With the new emphasis on improving graduate training in Africa's higher education, female graduate students in African universities could provide important insights to future research, practice, and policy, especially as subordinate voices (Mkandawire-Valhmu, Kako, Kibicho, \& Stevens, 2013).

\section{Methodology}

Our study uses the general principles of qualitative feminist research, specifically focus group interviews (FGIs). We completed an initial review of literature to identify and contextualize the gaps in existing knowledge, clarify our research questions, and design a semi-structured interview guide for our FGls. After obtaining ethics approval from the University of Alberta's Research Ethics Board and the ethics review authorities within the participating universities, we conducted $4 \mathrm{FGIs}$ with a total of 43 female graduate students as recommended by Krueger and Casey (2009). To place the experiences of female graduate students in a multidisciplinary context, we selected one regular institution and one institution of technology in both Nigeria and South Africa. The researchers selected institutions from South Africa and Nigeria as the two countries contribute to a large proportion of African gradutes. The participants were Master's and doctoral students from science, technology, business and social sciences. Participants were selected from the pool of registered (full-time and part-time) female graduate students in any of the four universities. The participants from the two South African universities included international students from Nigeria, Kenya and Zimbabwe completing their doctorates in south Africa.

Focus groups were conducted after participants had fully read the informed consent document and had their questions answered. FGls lasted approximately two hours, were audio recorded, and transcribed verbatim. The semi-structured interview schedule included questions about factors that mediate women's field of study, number of years spent in training, and career choices. The FGIs also explored female graduate students' representation and voice in decisions affecting their training as well as suggestions for improving graduate programs.

We employed one female graduate research assistant in each university to assist the research team in recruiting participants and conducting focus groups. These professionals were culturally familiar with our participants' experiences and were asked to transcribe each dataset. Two University of Alberta graduate students assisted with coding and thematic analysis of our findings. Data analysis was completed using NVivo10 qualitative data analysis software. The steps in data analysis included familiarizing the research team with the data and generating initial codes. Finally, we searched for, reviewed, refined, defined, and named emerging themes from the data to generate our initial report (Braun \& Clarke, 2006). Due attention was given to rigor in this study. The findings have in turn informed a 2018 comprehensive multi-institutional research proposal on graduate training in sub-Saharan Africa.

\section{Ethical Considerations}

A total of 4 focus group discussions were conducted with 43 African female students. Participants were recruited from the humanities, social sciences, as well as the (natural and applied) sciences. The principal investigator served as the main discussant for all focus group sessions in order to create a safe and comfortable space where students could share their experiences freely. No personnel or staff from the respective universities directly took part in the focus group discussions in their official capacity. All standard ethical procedures were followed with particular sensitivity to issues of confidentiality and anonymity. Recorded consent was given by participants and information detailing aims of the research was shared with the participants. All participants were made aware that they could withdraw from the 
research at any given time without any negative consequences. Given the sensitive nature of some of the issues discussed by the participants, the authors assigned arbitrary labels to each institution to maintain confidentiality. The institutions were therefore identified as FA01 and FA02 in Nigeria, and FA03 and FA04 in South Africa.

\section{Findings}

The findings of the study are analyzed in a thematic fashion, detailing the recurring concerns that resonate among female graduate students in the four universities. The themes are further explored in terms of national trends and histories, disciplinary concerns, and differences related to the structure and governance of each institution. The following are the major concerns shared by the students: financial challenges, limited sources of and dated curricular materials, institutional infrastructure and program logistics, academic supervision, and gender relations, including concerns about sexual harassment.

\section{Financial Challenges}

Financial challenges resonated in the four focus groups as a major concern faced by graduate students at all levels and in many disciplines. Participants explained that students live with different levels of precarity depending on available sources of funding. Some students could not even afford daily living expenses. In the words of a South African student, "because we want this education, we have to suffer economically as we are struggling to buy groceries" (FA03, p. 10). Institutions provide some level of financial support, another student from South Africa explained, but the amount is very small compared to the threshold of funding required to make it through graduate training. The limited funding base for her PhD program, she explained, didn't allow for balancing living expenses with expenses related to her research work. The latter, she pointed out, required having the necessary resources for books, travel, and other scholarly engagements. The lack of funding, most of the participants concurred, limited the capacity of students to pursue their training with vigor and ultimately negatively impacted the quality of their research output. A student from a South African institution highlighted how the lack of sufficient funding created a large and rapidly growing enrolment of part-time graduate students. She explained that many students prefer to pursue full-time programs but are not financially equipped to go that route:

I would prefer to be a full-time student staying in a residence, where there is Wi-Fi I have access for 24 hours, would like to be sitting there doing my work, go to see my supervisor and come back to do my work, that's what I would like to do. There is no funding. (FA03, $p$. 22)

Another student suggested that "for women, especially [those] ... who are single mothers, graduate education] becomes impossible" (FA04, p. 5).

Most of the participants agreed that graduate funding is unequally distributed across programs in favor of students in the sciences. The humanities, in their view, received far less funding than other fields. It is not uncommon, they explained, to see their counterparts in engineering receive more funding than graduate students in the social sciences and humanities. Addressing funding shortfalls, the participants unanimously agreed, would reduce a significant challenge faced by those already in training, remove a huge set of barriers that unjustly dictate who can pursue graduate training, improve research output, increase completion rates, and decrease the number of years students spend in graduate school. Funding constraints negatively impact on male and female candidates, but female postgraduate students often deal with the added strain of childcare expenses.

\section{Dated Curricular Materials, Limited Sources, and Rest- ricted Access}

Participants, especially those in the regular universities, noted that library materials are often outdated. Many also complained that laboratory equipment and supplies are in many cases unavailable, old, or in need of repairs. Focus group participants spoke of the difficulties that they encounter in doing their course work and research because of these impediments. All the participants expressed their frustrations about the highly restricted access to recent publications. One South African student articulated this problem very well: 
You find that sometimes you go through the material that would be helpful towards your research and then you find that the most good stuff [my school] does not have, you cannot have access, this is so recent this speaks more to my research like any other that you do not have access to it, the institution has not subscribed to it, whatever they have subscribe to its old material and then they would tell you they don't want old reading material. You have to get recent, but [they] do not have that recent material.(FA03, p. 9)

Many graduate students, the participants explained, resort to purchasing some of these publications on an already limited personal budget. In many instances, they further explained, graduate students are forced to make these purchases because their instructors or supervisors expect them to read and integrate the publications into their research. Given that research often entails some knowledge of broader literature about one's research topic, the range of publications often outstrips many students' purchasing power. These academics, a Nigerian student commented, are well aware that recent academic publications can be quite expensive regardless of whether they are online or physical copies. It is one thing to wrestle with accessing the necessary resources for one's academic career. It is another thing to make materials that cannot be freely accessed a requirement for students' success. The problem is best articulated by a Nigerian student: "The library doesn't have up-to-date books. The things we see there are older than 2000 and we are expected to make references of 2003 [and] upwards"(FA02, p. 4-5).

The challenges presented by the availability and quality of curricular materials will necessarily impact the quality of research produced by graduate students.

\section{Institutional Infrastructure and Support Systems}

Throughout the focus groups, participants identified what they considered serious structural problems that plague the broader education system and create challenges for graduate students and programs. South African students argued that, apart from the challenges discussed earlier, the poor enrolment of Black students can also be traced to gender roles and expectations that disadvantage women. Another participant vigorously criticized South Africa's history of racial segregation as the main culprit for the low enrolments of Black students in graduate programs:

I think even currently South Africa has a dual educational system. So there was a system that was designed for us Black people, even when Bantu education was abolished you find that, we did not have opportunities, resources and qualified teachers that prepared us for higher education. Even now you find when structural barriers are gone...there is not enough preparation for people to access those higher education institutions. (FA04, p. 8)

Participants also identified the economic disadvantages, poor quality of primary and secondary education, and the barrier presented by English as the main language of instruction as other challenges faced by South African Blacks. According to a South African participant, English was a difficult challenge as a Black woman from a disadvantaged social background. Gaining enough fluency in English language for the demands of graduate work required hard work and effort that more privileged students often take for granted.

Although most of the participants discussed the specific problems related to their programs, there was a shared concern about the lack of childcare for graduate female students who have young children. In two of the focus groups, we had to make accommodations for one participant who came with her infant. There was no readily available daycare facility or informal support system for these children. The discussion about childcare focused more on the individual instructor's level of tolerance for mothers who attend class with their infants or young children than on daycare as a necessary support service that academic institutions must provide. In the absence of affordable childcare, these mothers were left in a precarious situation; attending class was not a choice but a decision left to the discretion of individual instructors.

\section{Academic Supervision}

A great deal of the focus group discussions centered on the relationship between graduate students and their supervisors. While several students shared positive experiences, most of the participants had problems with their supervisors. For some students, a shortage of supervisors was the problem. Speaking from her own experience, one South African student 
commented,"You end up having one supervisor supervising more than 20 students, which is why you have more people in the system who are not moving out because of the lack of supervisors" (FA03, p. 10). Participants also noted that, in some cases, the lack of supervisors meant that a student could be assigned to supervisors who had little or no expertise in their proposed subject of study. A Nigerian student expressed her dissatisfaction that she was "given a supervisor that [did] not even know [her] area...[The] student is supposed to be directed by a supervisor who is in [their] field" (FA01, p. 14).

While the participants lamented the dismal state of graduate supervision, they also shared frustrations that also plagued supervisors. For one thing, many students are enrolled part time; a good number of them reside a great distance away from their institution. Communications often consisted solely of email. Due, in part, to the heavy student load academic supervisors carry, individual students do not receive the support they need. Many of them fail to make any appreciable progress towards completing their program. Supervisors appear to be caught in a never-ending cycle of dealing with students who have overstayed their welcome in the program and adding a new set of new students to the backlog. In the end, both sets of students hardly receive adequate supervision. As one of the Nigerian participants put it,

The supervisors or the lecturers, generally the workload on them is kind of, it's too much, because at times some of these lecturers, they have lecturing, supervising, they have certain administrative affairs... I don't know where I can pinpoint where the problem is. (FA01, p. 16)

Some of the students agreed with the views shared above. However, others noted that some academic supervisors might also be wrestling with a lack of expertise in addition to the challenges that the system presents. One South African student argued that "Not every good scholar is a good supervisor... The supervisors themselves need support so that the students start and finish, and students need support on how to navigate their PhD" (FA04, p. 10). Being a good supervisor, most of the participants agreed, is a skillset on its own and not necessarily one that is developed by simply acquiring a doctoral degree. In this regard, the students requested that a support system be set in place for supervisors, including regular training to hone their skills.

Overall, participants strongly emphasized the importance of having a knowledgeable and agreeable supervisor on the successful completion of their graduate program. One focus group interviewee from South Africa was very mindful of this crucial ingredient. Given the negative reputation of supervisors, she took time to identify a program based, in part, on the reputation of its supervisors: "I remember I wanted to register, but I was so scared to register... because of this issue of supervisors. They are not even communicating; everybody is just operating on their own" (FA03, p. 10). Given the negative reputation of supervisors in her initial program, she moved to an entirely different program where the supervisors were described as "supportive" (FA01, p. 10). It is vital, participants emphasized, that higher education institutions that offer graduate programs take steps to improve student supervision. The quality of program supervisors, in their view, is taken into consideration when students decide on what program to apply to.

A South African student expressed concern about the limited options students have when they are dissatisfied with the quality of supervision they experience:

Sometimes when things go wrong students actually don't know where to go and what to do...sometimes you do not know whether you are coming or going, you feel like there is no movement so you actually don't know what to do because primarily you do not want to offend or upset the supervisor because should that happen they might not be anyone else available to supervise you. (FA03, p.7)

\section{Gender Relations and Sexual Harassment}

Amidst the challenges encountered by participants in graduate school programs, many of which were experiences shared with their male counterparts, gender relations resonated loudly as a difficult terrain to navigate. Gender-related issues such as childcare and access to graduate training for single mothers were identified above, but the emphasis in this segment of the focus group discussions centered mainly on gender roles and societal expectations. One South African student cited what appeared to be a central issue for many Black women who 
wished to pursue graduate training:

I grew up in a place where men are the first priority, like as a Black human I would say if you are a woman you are expected to have children at a certain stage and get married... I always have to explain myself to people.(FA04, p. 3)

Black South African communities, in her view, place more emphasis on being a mother and raising one's children than empowering women to pursue higher education. Ambitious women like her have to balance these social expectations with their individual aspirations. This participant explained that family members exerted considerable pressure on her and attempted to persuade her to give up her career aspirations. It was even more frustrating for her when a male cousin was continually praised for enrolling in a PhD program and settings his sights on becoming a "doctor."

The significance as well as irony embedded in a gender dynamic that discourages women's career ambitions and accords a less than equal status to female high achievers compared to their male counterparts was succinctly expressed by another South African student:

It's like men were saying you don't have rights because you are a female, you are not supposed to challenge me ... You have people who look at you as sex objects. You had to make a way to make them understand that yes you're a man and I am a female but I can also do what you can do, you don't have to say statements to me just because I am an African woman. (FA03, p. 3)

Graduate programs present various problems for both male and female students. Female students, most of the participants agreed, are often treated as second-class citizens who must defend their reasons for "invading" the graduate academic space, prove that they can handle the pressure, and continually demonstrate that their training is a worthwhile pursuit. In the words of another student, simply being a female with thoughts of your own already places many female students in opposition to society:

There is a feeling that as a female you must always be apologetic, you must apologize for your views. As soon as you are a female who has views you are not accepted in the society. When you are challenging men's views, it feels like you are in conflict with the society. (FA03, p. 3)

For some of the students in the focus groups, pursuing a postgraduate education meant facing the pressures of family and friends to get married and have children. They must also contend with the irritating elements of academia, which they consider a hostile environment for women. A Nigerian student sounded a warning to female students about the often-expected pressures from family members, especially parents, to marry as they move up the ladder of higher education:

Don't allow your parent to push you [to get married] because at the end you bear your cross on your own... You are left with your own life and marriage. You cannot rush in. We have a lot of ... single parents here... It is because of rushing because your parents forced you to marry... You have to think and you have to put your feet down on whatever you want to do. (FA01, p. 22)

While some female students may be inclined to succumb to family pressures, in the South African context of single parenthood, all the participants agreed that women should make their own decisions. Everyone, male and female alike, they argued, has a right to think and act for themselves. They agree, however, that the daily struggles to assert one's rights can wear some women out.

Sexual harassment was identified as an endemic, system-wide, and taken-for-granted challenge faced by female graduate students. Participants shared many instances of sexual harassment inflicted on female students by both male lecturers and male students. Some female students complained of unwanted comments regarding their physical appearance as well as requests by lecturers to have them sit at the front of the class or go out with them. One Nigerian student quoted a lecturer as saying, "I want to hear your beautiful voices, come to the front" (FA01, p. 9). Another Nigerian student related a sad tale of how male classmates manipulated her to take on the uncomfortable task of contacting lecturers or getting materials from them for class activities. On several occasions she felt she was being used to entice lecturers who had poor attendance to come to class:

They were like you don't know that we're using you as a support in front of those lecturers 
that maybe [he will] hear your voice [and] like to come to class... One of the lecturer just come in one day [and asked], "Can I hang out with you?" I was like no sir I'm very busy and I don't go out... I need to lie to that lecturer that I'm married. (FA01, p. 8)

Of greater cause for concern, one South African student noted, is the exchange of sexual favors by female students for grades. According to her, "there were students who got extra marks because they were having relationships with the lecturers" (FA03, p. 4). She was uncertain whether these relationships were "forced or agreed upon" (p. 4). If unwanted comments from lecturers about female student's physical appearance or the sounds of their voice were not troubling enough, one student remarked,"torture was when the lecturer came to a student and want to sleep with you for some reasons. A person who is like my grandfather. It doesn't make sense. It's crazy!" (FA03, p. 4). Another student expressed her dismay at inappropriate touching by a lecturer:

I was preparing for my marriage... so one of my lecturers he picked me ... I was going home he picked me ... So I get into the car when we're moving, he now put his hand on my lap and said, "Where will you be this weekend? I'm going to a conference. I said, "Sir would you allow me to tell my dad? (FA01, p. 11)

As noted earlier, gender relations in Africa's higher education point to an established institutional and administrative culture that enshrine male stakeholders as the protectors of the status quo. As subordinate "others," whose presence is, for the most part, considered a privilege, female students are more vulnerable than men to the unequal relations of power between academics and graduate students. Sexual harassment, in this context, could easily flourish where there are neither support systems that could create safe spaces for female students nor effective policies to deter potential perpetrators. Given its scale, diversity, and impacts, as reported in existing (albeit spare) literature, sexual harassment of female students should receive far more attention in Africa's institutions of higher education. The insights shared by participants in this study reflect the dismal response sexual harassment receives. As a taken-for-granted element of everyday life in academia, female students must find ways to deflect or navigate the challenges of sexual harassment. The low profile that sexual harassment currently commands may not be totally disconnected from their under representation in high level decision-making positions in both higher education and broader structures of social governance.

\section{Discussion:}

\section{Questions of Voice, Power, and Responsibility in Graduate Training}

This study only highlights one crucial point: student voice in Africa's higher education cannot be discounted if the stakeholders who presently dominate the forum are serious about transforming the system. It is safe to say that the problems associated with funding, curricular materials, institutional infrastructure, academic supervision, and gender relations and sexual harassment constitute endemic challenges to higher education systems worldwide. Although the problems pertaining to funding, curricular materials, institutional infrastructure and academic supervision serve as barriers to male and female students, the situation of female students are more precarious due to gender stereotyping, additional family and childcare responsibilities and a lack of role models and sexual harassment. The plight of female students therefore need more attention from policymakers and manahement. The nature, history, causes, and the measures stakeholders take to eliminate or mitigate their impact depend on the context. The experiences of participants in this study, however, stress how acutely the quality of Africa's higher education systems have depreciated. These experiences signal a downward trend that calls for action on every front. The diversity of institutional contexts that mediate these experiences highlight a number of troubling trends emerging in Africa's higher education systems: increasing politicization of institutional administration, severe cuts in public funding, ever increasing demand for higher education that continues to outstrip supply, and high levels of unemployment for graduates.

Recent investments by Western funding agencies into Africa's higher education are a welcome development, considering the dire need for capacity building. It is, however, doubtful that such investments will build any appreciable capacity. Structured as institutional collaborations, many of these initiatives are not necessarily designed to build or sustain longterm scholarly linkages. Tackling the acute challenges identified by graduate students in this 
study will require institutional collaborations that infuse expertise, funding, and curricular materials into Africa's academic institutions. The impact of these collaborations will depend on crucial factors such as how long they can be sustained to allow for capacity building, the material resources, and scholarly expertise that various actors bring into the relationship, and the importance accorded to graduate training.

The experiences of female graduate students in this study highlight their marginalized status in higher education as students, scholars, and decision makers. More importantly, their insights into what happens in their various institutions portray the varying degrees of vulnerability they live with, given the limited or lack of support systems that could address challenges unique to their being female. The low priority given to these support systems cannot simply be attributed to a lack of resources. Concerns related to childcare or gender relations of power could seriously impact on the capacity of African women to pursue graduate training as well as the quality and outcome of that training. Neglecting these concerns points, in a sense, to the social utility accorded to women as academics as compared to their male counterparts.

Based on where marginalized females remain in Africa's higher education institutions, reversing the trend will require more than substantial infusions of capital to develop physical infrastructure and expand existing curricular resources. It will demand the political will to pursue new visions in defiance of the status quo. It is only since the turn of the millennium that questions of voice, power, and responsibility in culture and administration of African higher education institutions are beginning to gain some currency (Mama, 2003).Recent feminist scholarship in the field firmly underscores the fact that the gains females have made so far in these academies have not led to any significant shifts in gender relations of power, roles, and opportunities in their favor (Odejidi et al., 2006).

Beyond the lack of student voice, the debate on Africa's higher education has not given sufficient attention to incorporating gender perspectives into graduate training policies and practices. This pattern is not unconnected with the women's low profile in African higher education institutions, especially as decision makers (Odejidi et al., 2006). Women are often relegated to positions that place them as subordinate "others" whose presence in the ivory tower can be tolerated but not totally embraced (Johnson, 2015; Airini et al., 2011). Even though female graduates are improving their representation significantly at master's and doctoral levels in South Africa, many African scholars highlight the under representation of especially African women amongst senior academic and management ranks at universities (Govinder et al., 2014; Seshoka, 2014).

It is important to note that gender inequities in contemporary Africa are, in part, the product of a colonial history that created asymmetries in gender relations within and outside the family to women's disadvantage (Onayemi, 2007; Robertson, 1987). These historical reconfigurations are also reflected in the gendered hierarchies embedded in the structure and social relations that govern Africa's higher education systems (Gaidzanwa, 2007; Morley, 2006). Universities were specifically designed to produce a community of male elites that drive the momentum for social progress in postcolonial Africa; women were trained to serve as housewives and hostesses to the emerging male elite (Abdi \& Cleghorn, 2005).As the major actors and ideal leaders in higher education, elite men were not expected to be burdened with roles that hinder their capacity to pursue their socially appointed offices. In contrast, women's career aspirations were encoded into their "primary" roles as wives and mothers (Nwauwa, 1994; Rathgeber, 1991).

Research that puts students' perspectives center stage will, in the long term, have policy implications that could propel some of the transformative strives that all stakeholders seek. ly and

\section{Implications for Policy, Practice, and Future Research}

Clearly, the first step towards creating sustainable policies for future practice is to expand the knowledge base that informs the debate on higher education and graduate training. It is particularly important to bring students, especially women students, into this debate - as actors and critical agents of change in their own right. We must specifically examine the intersections of race, gender, and class with respect to the impact that these factors have on various communities of students in Africa's higher education system. With a more complete 
knowledge base from which to work, future policymakers will be able to explicitly identify the shortcomings of their current policies and correct them.

Although monetary investment may help to alleviate some of the financial burden faced by female students in the form of dated scholarly information and precarity, the above discussion makes it obvious that addressing gender inequities requires redefining, at the basic societal level, the roles that we force onto women and men. The postcolonial feminist perspective taken in this study illustrates that although independence in Africa has been achieved, relics of colonialism are still apparent in universities throughout Africa. Because, as discussed by Nkomo and Ngambi (2009), universities are major sites of cultural practice, identity formation, and symbolic control, they offer a unique opportunity to shape the attitudes of African culture and offer benefits at all levels of society. Making such a stride requires the conscious acknowledgment of the remnants of colonial influence built into the very structure of the academy in addition to a willingness to achieve change from within; we must admit that our system is problematic before a remedy can be achieved.

Support systems that consider burdens placed disproportionately on women - that is, those that are associated with the wife or mother role such as childcare and maternity benefits -must be buttressed not only by monetary support. Clowes (2015) suggests that by bringing to light the largely invisible privileged identity that men have inherited from the colonial era and addressing how this identity negatively impacts both men and women in society, we may be able to overcome some of beliefs at the root of the resistance of equality. Indeed, as men are central to many of the concerns expressed by graduate students in our FGls because they often have a more direct and privileged access to harass women than their female counterpart. It is therefore important to create forums where this privilege is explored in ways that could convince men that equality would benefit them too.

Female students who attend universities have an obvious stake in the outcomes and experiences of their higher education, so we must include their input when creating new policies if we expect these policies to have any appreciable impact. Currently, there is a lack of accountability regarding the quality of supervision for graduate students, which is leading to more negative experiences overall - not only for women but for all students. Based on the FGIs, students suggest that system-wide strategies need to be put in place for properly training supervisors. These strategies must capture the specificities of institutional cultures to ensure competency and compatibility with students' needs; teaching awareness of and solutions to the power imbalance between supervisor and student must be part of this training. Encouraging co-authorship between students and their supervising professors also offers the opportunity for students to form a positive relationship with their supervisors. To address the troubling trend of sexual harassment in the university setting, policymakers must be prepared to take a firm stance against its presence and provide a safe community in which female students are encouraged to report misconduct of their superiors and peers without fear of reprisal.

The creation of writing centers to support the development of important skills for graduate students could increase not only the completion of graduate degrees by female students (and therefore increase the available female hiring pool for university institutions) as suggested by Archer's (2010) study, but also make obvious the benefits of having higher numbers of "productive" female researchers as critical agents of change in the broader project of institutional transformation.

These preliminary interventions, if implemented in cohesively, could significantly contribute to mitigating the serious challenges female graduate students face in African universities. These interventions, it must be stated, would serve only as beginning points for addressing systemic gender inequities in African universities. As the experiences of female students in the four African universities in this study show, dismantling gender inequities will require a significant restructuring of how higher education is organized and delivered in Africa, which includes a transformation in the institutional cultures that enable systemic sexism to thrive.

\section{References}

Abdi, A., \&Cleghorn, A. (Eds.). (2005).Issues in African education: Sociological perspectives. London: Palgrave. 
Adeogun, M. (2006). The challenges of a modern tertiary education system: Paradigm shifts for educators and information professionals in Sub-Saharan Africa. African Journal of Library, Archives and Information Science, 16(1), 45-52.

African Higher Education Summit. (2015, March 10). Dakar, Senegal. Retrieved from http://summit. trustafrica.org/media-centre/

Airini et al (2011) Learning to be leaders in higher education. Education Management Administration \& Leadership, 39(1), 44-62.

Akuffo, H., Freeman, P., Johansson, E., Obua, C., Ogwal-Okenge, J., \& Waako, P. (2014). Doctoral education and institutional research capacity strengthening: An example at Makerere University in Uganda (2000-2013). Higher Education Policy, 27(2), 195-217.

Aina, T. (2010). Beyond reforms: The politics of higher education transformation in Africa. African Studies Review, 53(1), 21-24.

Airini, S.C., Conner, L., McPherson, K., Midson B., \& Wilson, C. (2011). Learning to be leaders in higher education: What helps or hinders women's advancement as leaders in universities. Educational Management Administration \& Leadership, 39(1), 44-62.

Allais, S. (2017). Towards measuring the economic value of higher education: lessons from South Africa. Comparative Education, 53(1), 147-163. doi.org/10.1080/03050068.2017.1254985

Amadi-Echendu, A., Phillips, M., Chodokufa, K. \& Visser, T. (2016). Entrepreneurial Education in a Tertiary Context: A Perspective of the University of South Africa. International Review of Research in Distributed and Open Learning, 17(4), 21-35.

Archer, A. (2010). Challenges and potentials for writing centres in South African tertiary institutions. South African Journal of Higher Education, 24(4), 495-510.

Braun, V., \& Clarke, V. (2006). Using thematic analysis in psychology. Qualitative Research in Psychology, 3(2), 77-101.

Carnegie African Diaspora Fellowship Program (CADFP). (2018). Retrieved from: https://www.iie.org/ Programs/Carnegie-African-Diaspora-Fellowship-Program

Cherney, A., Povey, J., Boreham, P., Ferguson, M.,\& Head, B. (2015). The utilization of social science research: The perspectives of academic researchers in Australia. Journal of Sociology, 51(2), 252-270.

Cloete, N., Mouton, J., \& Seppard, C. (2015). Doctoral education in South Africa. Somerset West: African Minds.

Clowes, L. (2015). Teaching masculinities in a South African classroom. Critical Studies in Teaching and Learning,3(2), 23-39.

Clowes, L., \& Shefer, T. (2013)."It's not a simple thing, co-publishing”: Challenges of co-authorship between supervisors and students in South African higher educational contexts. Africa Education Review, 10(1), 32-47.

Desmennu, A. T., \& Owoaje, E. T. (2018). Challenges of research conduct among postgraduate research students in an African University. Educational Research and Reviews, 13(9), 336-342.

Dlamini, R. 2016. The global ranking tournament: A dialectic analysis of higher education in South Africa. South African Journal of Higher Education, 30(2), 53-72.

Francis, J., Kilonzo, B. and Nyamukondiwa, P. (2017). Student-perceived criteria for assessing university relevance in community development. South African Journal of Science, 112(11/12), 1-7.

Frick, L., Motshoane, P., McMaster, C. \& Murphy,C. (2016). Postgraduate study in South Africa: Surviving and succeeding. Stellenbosch: Sun Press.

Gaidzanwa, R. (2007). Alienation, gender and institutional culture at the University of Zimbabwe. Feminist Africa, 8, 60-82.

Govinder, K.S., Zondo, M.P., \& Makgoba, M.W. (2013). A new look at demographic transformation for universities in South Africa. South African Journal of Science,109,(11/12). https://doi.org/ $10.1590 /$ sajs.2013/20130163

Gwakwa, M. (2016). Tertiary Education Curricula Internationalisation in Southern Africa: Its u.Impact on Global Employment Opportunities. Journal of Education and Practice, 7(13), 78-86.

Higgs, P. (2016). The African renaissance and the transformation of the higher education curriculum in South Africa. Africa Education Review, 13(1), 87-101. https://doi.org/10.1080/18146627.2016.1186370 
Ikejiani, O. (ed.) 1960. Nigerian Education. Lagos: Longmans.

Ilie, S. and Rose, P. (2018). Who benefits from public spending on higher education in South Asia and subSaharan Africa? Compare: A Journal of Comparative and International Education, 48(4), 630-647. doi.org/10.1080/03057925.2017.1347870

Illing N. (2012) Funding drought hits experimentally based South African researchers and their graduate students. South African Journal of Science, 108(3/4), 1-5.

Iwu, R.U. \& Azoro, A.V. (2017). A study on the barriers to participation of females in science, mathematics and technology education in Imo State the way forward. Educational Research and Reviews, 12(17), 832-838.

Johnson, A.T. (2015). Performing and defying gender: An exploration of the lived experiences of women higher education administrators in sub-Saharan Africa. Educational Management Administration and Leadership, 42(6), 835-850.

Johnson, A.,\& Hoba, P. (2015). Rebuilding higher education institutions in post-conflict contexts: Policy networks, process, perceptions and patterns. International Journal of Educational Development, $43,118-125$.

Jowi, J. (2012). African universities in the global knowledge economy: The good and ugly of internationalization. Journal of Marketing for Higher Education, 22(1), 153-165.

Kandiyoti, D. (2010). Bargaining with patriarchy.In C. McCann \&S.-K. Kim (Eds.), Feminist Theory Reader: Local and Global Perspective (pp. 80-89). London: Routledge.

Krueger, R.A., \& Casey, M.A. (2009). Focus groups: A practical guide for applied research (4thEd.). Thousand Oaks, CA: Sage Publications.

Mama, A. (2003). Restore, reform but do not transform: The gender politics of higher education in Africa. Journal of Higher Education in Africa/Revue del'enseignementsupérieuren Afrique, 1(1), 101-125.

Mkandawire-Valhmu, L, Kako, P., Kibicho, J.,\& Stevens, M. (2013). The innovative and collective capacity of low-income East African women in the era of HIVIAIDS: Contesting Western notions of African Women. Health Care for Women International, 34(3/4), 332-350.

Mohanty, C.T. (1988). Under Western eyes: Feminist scholarship and colonial discourses. Feminist Review,30, 61-88.

Morley, L. (2006). Hidden transcripts: The micro-politics of gender in commonwealth universities. Women's Studies International Forum, 29(6), 543-555.

Mtebe, J. and Raisamo, R. (2014). Investigating perceived barriers to the use of open educational resources in higher education in Tanzania. International Review of Research in Open and Distributed Learning, 15(2), 249-271.

Muraraneza, C., Mtshali, F. and Mthembu, S. (2016). Research supervision: Perceptions of postgraduate nursing students at a higher education institution in KwaZulu-Natal, South Africa. African Journal of Health Professions in Education, 8(2), 135-139.

Nkomo, S. M.,\& Ngambi, H. (2009). African women in leadership: Current knowledge and a framework for future studies. International Journal of African Renaissance Studies, 4(1), 49-68.

Ntshoe, I. and Selesho, M. (2014). Institutional ranking in a differentiated higher education in South Africa. South African Journal of Higher Education, 28(5), 1554-1574. DOI: https://doi.org/10.20853/28-5-408

Nwauwa, A. (1994).Imperialism, academe, and nationalism: Britain and university education for Africans, 1860-1960. London: F. Cass.

Oanda, I., \& Sall, E. (2014). From peril to promise: Repositioning higher education for the reconstruction of Africa's future. International Journal of African Higher Education, 3(1), 51-78.

Odejidi, A.,Akanji, B.,\& Odekunle, K. (2006). Does expansion mean inclusion in Nigerian higher education? Women's Studies International Forum, 29(6), 552-561.

Okeke-Ihejirika, P. (2017). Asserting agency by negotiating patriarchy: Nigerian women's experiences within university administrative structures. Journal of Global South Studies 34(1), 1-21.

Oketch, M. (2016). Financing higher education in sub-Saharan Africa: some reflections and implications for sustainable development. HigherEducation, 72(4): 525-539.

Onayemi, F.(2007). Finding a place: Women's struggle for political authority in classical and Nigerian societies. Women's History Review, 16(3), 297-309. 
Ondari-Okemwa, E. (2011). The strategic importance of identifying knowledge-based and intangible assets for generating value, competitiveness and innovation in Sub-Saharan Africa. South African Journal of Libraries and Information Science, 77(2), 138-154.

Robertson,C. (1987). Developing economic awareness: Changing perspectives in the studies of African women, 1976-1986. Feminist Studies, 13(1), 97-135.

Rogers, K. and Picard, M. (2017). A Systematic Review on Mobile Learning in Higher Education: The African Perspective. Turkish Online Journal of Educational Technology - TOJET, 16(1): 1-18. https://files. eric.ed.gov/fulltext/EJ1124918.pdf

Sall, E., \&Oanda, I. (2014). Revitalisinghigher education for Africa's future. Journal of Higher Education in Africa/Revue de L'enseignement supérieuren Afrique, 12(2), 95-107.

Seshoka, L. (2014, October 24). No more transformation excuses. Mail \& Guardian [City]. Retrieved from: https://mg.co.za/article/2014-10-24-no-more-transformation-excuses

Shanghai University Rankings (2017). Retrieved from: https://www.timeshighereducation.com/student /news/shanghairanking-global-ranking-academic-subjects-2017-results

Shrivastava, M.,\& Shrivastava, S. (2014). Political economy of higher education: Comparing South Africa to trends in the world. Higher Education, 67(6), 809-822.

Teferra, D., \&Altbach, P. (Eds.). (2003). African higher education: An international reference book. Bloomington, IN: Indiana University Press.

Tuhereze, E. (2015, November 4). Uganda and Sweden sign five-year USD 32 million research collaboration agreement. Makerere University News. Retrieved from:https://news. mak.ac.ug /2015/11/uganda-and-sweden-sign-five-year-usd-32million-research-collaboration-agreement.

Van Wyk, B., \& du Toit, A. (2016). A survey of sustainable curation in research repositories of higher education institutions in Southern Africa. African Journal of Library, Archives and Information Science, 26(2), 107-116.

Woolley, R., Sánchez-Barrioluengo, M., Marceau, J.,\& Turpin, T. (2015). Research collaboration in the Social Sciences: What factors are associated with disciplinary and interdisciplinary collaboration? Science and Public Policy, 42(4), 567-582.

Wyk, N. C., Coetzee, I. M., Havenga, Y., \& Heyns, T. (2016). Appreciation of the research supervisory relationship by postgraduate nursing students. International Nursing Review, 63(1), 26-32. 